\title{
Article
}

\section{Group cognitive behavioural therapy for stroke survivors with depression and their carers}

Ward, SK, Turner, A, Hambridge, JA, Halpin, SA, Valentine, M, Sweetapple, A, White, J and Hackett, Maree

Available at http://clok.uclan.ac.uk/16127/

Ward, SK, Turner, A, Hambridge, JA, Halpin, SA, Valentine, M, Sweetapple, A, White, J and Hackett, Maree ORCID: 0000-0003-1211-9087 (2016) Group cognitive behavioural therapy for stroke survivors with depression and their carers. Topics in Stroke Rehabilitation, 23 (5). pp. 358-365. ISSN 1074-9357

It is advisable to refer to the publisher's version if you intend to cite from the work. http://dx.doi.org/10.1080/10749357.2016.1143706

For more information about UCLan's research in this area go to http://www.uclan.ac.uk/researchgroups/ and search for <name of research Group>.

For information about Research generally at UCLan please go to http://www.uclan.ac.uk/research/

All outputs in CLoK are protected by Intellectual Property Rights law, including Copyright law. Copyright, IPR and Moral Rights for the works on this site are retained by the individual authors and/or other copyright owners. Terms and conditions for use of this material are defined in the policies page.

\section{CLoK}

Central Lancashire online Knowledge www.clok.uclan.ac.uk

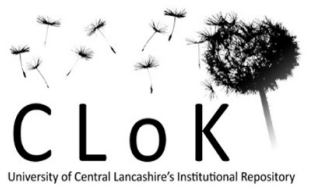


Title: Group cognitive behavioural therapy for stroke survivors with depression and their carers

\begin{abstract}
Background: Depression in stroke survivors is common, leads to poorer outcomes and often not treated. A group cognitive behavioural therapy (CBT) program (Brainstorm) for stroke survivors with depression, and their carers has been running as part of usual care since 2007.
\end{abstract}

Objective: To evaluate the implementation and acceptability of Brainstorm, a closed group intervention consisting of up to 10 sessions of education, activity planning, problem solving and thought challenging.

Methods: Participating stroke survivors and their carers complete assessment measures at baseline, post-treatment and 1-month and 6-months follow-up. A mixed models for repeated measures data was conducted with depression and anxiety scores for stroke survivors (Beck Depression Inventory-II; Hospital Anxiety and Depression Scale) and the assessment of depression, anxiety and carer burden for carers. Acceptability was assessed by session attendance and written and open participant feedback upon completion of the program.

Results: Forty-eight community dwelling stroke survivors and 34 carers attended Brainstorm, with a median attendance of $88 \%$ of sessions. Follow-up assessments were completed by 77\% (post-treatment), 46\% (1-month) and 38\% (6-month) of stroke survivors. Stroke survivors’ depression scores decreased from baseline to post-treatment $(p<.001)$; maintained at 1 -month $(p<.001)$ but not at 6-month $(\mathrm{p}=.056)$. Anxiety scores decreased between baseline and 1-month ( $p=.013)$. Carer burden, depression and 
anxiety scores at 1-month and 6-month follow-up, for carers, were all reduced when compared with baseline $(p<.05)$.

Conclusion: The Brainstorm group intervention for depression in stroke survivors appears to have been effectively implemented and is acceptable to stroke survivors and carers.

Keywords: Cognitive behaviour therapy, depression, group therapy, stroke, anxiety, carers 


\section{Introduction}

Approximately one-third of stroke survivors experience depression in the year following stroke ${ }^{1}$ which may impede rehabilitation, reduce socialisation and increase mortality risk..$^{2-3}$ The management of stroke survivors' behaviours and provision of emotional support has been associated with negative caregiver outcomes, such as reduced social functioning, well-being and physical health ${ }^{4}$ and increased caregiver emotional distress. ${ }^{5}$

Reliable empirical evidence to guide clinical management of post-stroke depression is limited. ${ }^{6}$ A Cochrane review provided tentative support for the use of antidepressant medication for depression in stroke survivors; however caution was advised due to side effects and unknown risks associated with these medications. ${ }^{6}$ Potential benefit of psychotherapeutic interventions for depression treatment post-stroke has been difficult to ascertain due to small number of studies ${ }^{6}$ and methodological limitations including small sample size, lack of treatment manual and poor experimental design.

Cognitive behaviour therapy (CBT) is a relatively brief, structured psychotherapy considered particularly effective in the treatment of mild to moderate depression in the general population ${ }^{7-8}$ and with depressed older adults. ${ }^{9}$ While individually delivered CBT has been shown to reduce depressive symptoms in stroke survivors, ${ }^{10-11} \mathrm{a}$ randomised controlled trial failed to demonstrate superiority over an attention control or standard care. ${ }^{12}$ However, more recently a behavioural intervention was found to be effective in treating depression in stroke survivors with aphasia. ${ }^{13}$ Further studies are needed to develop and evaluate effective psychotherapeutic interventions for depression in stroke survivors.

Group CBT is estimated to cost half that of individually administered therapy and is able to treat more people using the same resources. ${ }^{14}$ This makes group CBT attractive 
for services with limited resources, including stroke services that may have minimal access to clinical psychologists. ${ }^{15}$

A group CBT program, Brainstorm, was developed for outpatient stroke survivors experiencing symptoms of depression. This program was adapted from an existing group CBT program for cardiac rehabilitation outpatients. ${ }^{16-17}$ As part of the program, participants completed pre- and end of treatment outcome measures, with follow-up at 1 and 6 months post treatment.

The aim of the present study was to examine the feasibility of the Brainstorm group CBT program and acceptability for stroke survivors experiencing symptoms of depression and their carers.

The primary hypothesis was that Brainstorm could be successfully implemented and would be acceptable to stroke survivors and their carers. The secondary hypotheses were that the group CBT intervention would result in lower depression scores for stroke survivors at the end of treatment (indicating improved mood) and that this reduction would be maintained at 1 month and 6 month post intervention. It was expected that stroke survivors would demonstrate an overall reduction in symptoms of anxiety, while carers would demonstrate reductions in depression, anxiety and carer burden. 


\section{Methods}

\section{Design and setting}

Data were collected as part of a service evaluation of a clinical program. No control group was used. Data were available from eight Brainstorm CBT programs conducted between March 2007 and June 2013.

\section{Participants and procedures}

The program was open to stroke survivors aged $\geq 18$ years with depressive symptoms (as determined by their referring clinician), with intact receptive communication, able to read, communicate verbally and complete ‘tick’ boxes on questionnaires independently. Exclusion criteria included major cognitive impairment or dementia; or non-English speaking. Suitability for the group program was determined via clinical judgement of referring clinicians and group facilitators. No screening tests for mood disorders were routinely used to assess eligibility, nor was antidepressant usage documented.

Participants either self-referred or were referred by health professionals within government and non-government inpatient and outpatient stroke services. All interested and eligible stroke survivors were offered treatment. Stroke survivors were asked to attend the group with a support person (“carers”), but were not excluded if they chose to attend alone. Carers, while not the target group, were included to benefit from CBT strategies personally and to assist stroke survivors in their recall and use of strategies outside of the group.

Individual baseline assessment occurred at the initial group session and the end of treatment assessment at the final Brainstorm session. Participants provided verbal and anonymous written feedback during the final session. Participants were also mailed questionnaires to complete at 1 and 6 months post-intervention. 


\section{Intervention}

Brainstorm is a closed group CBT program consisting of between 7-10 sessions of 2-3 hours duration. The first group programs consisted of 7 or 8 weekly sessions. The program was extended by two sessions for groups 6-8 (6 weekly sessions, followed by 2 fortnightly sessions, and then 2 sessions a month apart) as preliminary data analysis suggested a loss of improvement in depressive symptoms by 6 months post-treatment. The additional sessions allowed more time for the delivery of the same content. Groups were facilitated by either 2 clinical psychologists or a clinical psychologist and a social worker or occupational therapist.

The cognitive and behavioural component of the Brainstorm program focuses upon improving mood by increasing activities, motivation and socialisation and in developing more adaptive cognitions. Brainstorm uses a manualised 'tool kit' approach; likening CBT strategies to maintenance tasks (Table 1). Each session included a program overview; review of homework from the past session; new information and new homework tasks; and a session summary. CBT techniques included: psycho-education, mood monitoring, activity monitoring and planning, thought monitoring and challenging. Problem solving skills included brainstorming, structured problem solving, goal setting, prioritising and motivating tools. Participants were encouraged to use these skills to deal with depression, anxiety and problems with day to day living. Some separate group time for stroke survivors and carers provided carers with a confidential arena to discuss difficulties in providing support for stroke survivors and allowed CBT strategies that targeted stroke survivor and carer-specific concerns.

All participants received a manual in the first session that included session information, examples, additional reading and a separate ‘daily diary’ for homework tasks. The participants' manuals were written in large font with double-spaced lines and tick-box 
options suitable for stroke survivors with a range of physical and cognitive disabilities and those with mild dysphasia, and approved by a speech pathologist with stroke expertise.

\section{Measures}

Stroke survivors completed BDI-II, HADS anxiety and depression subscales (HADSA, HADSD) at each assessment. Carers completed BDI-II, HADSA, HADSD and the Oberst Caregiving Burden Scale (OCBS). Participants received feedback on their depression and anxiety scores at the initial and final treatment sessions.

As the outcome measures were given as part of a service evaluation project, completion of the measures was deemed sufficient consent, as participants who completed the measures did so with full knowledge that the results would be used to evaluate the program. Analysis of the outcome data and publication and dissemination of results were approved by the relevant ethics committees.

\section{Participant feedback}

Acceptability was assessed by session attendance and participant feedback. A separate process evaluation was not conducted. Participants provided anonymous written and open feedback about the Brainstorm group during their final session. Participants responded to 10 questions using a 5-point Likert scale, adapted from Edelman et al. ${ }^{18}$ Responses ranged from 1 (not at all); to 5 (very much) on questions relating to facilitation, enjoyment, benefits of group setting and usefulness of the manual and daily diary. Participants provided open feedback about the positives and negatives of the program and were able to suggest changes.

\section{Depression and anxiety}

The 21 item BDI-II ${ }^{19}$ and 14 item HADS $^{20}$ are both widely used and validated measure of self-reported depression and anxiety in people with stroke. ${ }^{21-22}$ Each item on the 
BDI-II is scored from 0-3 (total score range 0-63) with recommended severity categories of depression: Minimal (0-13); Mild (14-19); Moderate (20-28); and Severe (29-63). ${ }^{19}$ The HADS has a 7-item anxiety subscale (HADSA) and a 7-item depression subscale (HADSD). Each item is scored from 0-3 (total subscale score range 0-21), with recommended severity categories of: Minimal (0-7); Mild (8-10); Moderate (1113); and Severe (14-21) depression or anxiety.

\section{Caregiver Burden}

The 15 item Oberst Caregiving Burden Scale (OCBS, 4) assesses time requirement and difficulty of tasks provided by caregivers, rating the time involved in a specific task (ranging from none to a great amount, scored 1-5); and the difficulty of performing the task (ranging from not difficult to extremely difficult, scored 1-5). Summed scores provide total sub-scores for time and difficulty (ranging from 15-75) with higher scores indicating greater time spent or difficulty with tasks. ${ }^{4}$

\section{Analysis}

Data were analysed with IBM SPSS Statistics for Windows (version 20.0; SPSS, Chicago, IL, USA). Significance reported a priori as $\alpha=.05$. Data deemed missing at random was dealt with according to questionnaire-specific guidelines. ${ }^{4,22}$ Missing data were imputed, where permissible, by averaging individual participants' scores within a subscale.

Linear mixed models were created for all outcomes to determine changes from baseline to end of treatment, and again at 1 and 6 months post-treatment. This approach to analysing repeated measures data ensured all participants were included in the analysis. Models were tested with 3 covariance options (Compound Symmetry; Toeplitz and Unstructured/General), with best fit determined by the lowest Akaike’s Information Criteria (AIC) and Schwartz’s Bayesian Criterion (BIC) values. 


\section{Results}

\section{Participant Characteristics}

Eighty-two participants started the program, including 48 stroke survivors (59\%; n=31 male; mean age 66.0, SD 11.6 years; median time since stroke 15 months; $71 \%$ one prior stroke, 29\% 2-3 prior strokes) and 34 carers (41\%; $n=7$ male; mean age 62.8 , SD 15.0 years). Thirty-seven (77\%) stroke survivors and 24 (71\%) carers completed the end of treatment assessment (Figure 1).

Median attendance was 88\% for all stroke survivors with 17 (35\%) attending all sessions; 12 (25\%) missing only one session; and 5 (10\%, from different groups) attending one session only. For those who attended 25\% or less of sessions, there were no significant differences in proportions of males, or baseline BDI-II, HADSA or HADSD scores, although of these participants, the average age of stroke survivors and carers was 60 years, 7 years younger than those who attended most sessions ( $p=.017)$. As the program was part of a clinical service, participants were not contacted to ascertain reasons for discontinuation.

\section{Participant Feedback}

Fifty-three participants (87\%) provided anonymous feedback and reported high satisfaction with the program. All respondents rated "How helpful was it being in a group with people in a similar situation” either 4 (“quite a lot”) or 5 (“very much”). Questions about enjoyment, helpfulness and leader quality had average ratings $>4$. The completion and ease of homework items (3 questions) had the lowest ratings, where responses ranged from 1 'not at all’ (1 participant) to 5 ‘very much’ (43 participants) with a median response of 4 'quite a lot'. Nineteen percent of participants rated homework as 1 or 2, indicating that this part of the manual could be improved. 
Suggestions for changes (obtained from open feedback at the final session) were primarily practical (program location; easier building access; reduced travel time). Resources did not allow for a full qualitative exploration of participant feedback.

\section{Mixed Models Analysis for Stroke Survivors}

Ages, gender, numbers of strokes, time since stroke or percentage of sessions attended were not significant in the models for BDI-II, HADSD and HADSA. HADSD scores were not significantly different for the 8 CBT groups. Baseline BDI-II and HADSA scores showed differences between groups (group 4 having significantly higher and group 7, significantly lower scores; Table 2).

\section{Depression}

Linear mixed model analysis found significant effects on the BDI-II for time $(F(3,61.64)=9.85, p<.001)$ and group $(F(7,42.42)=2.26, p=.048)$ but groups did not change differently over time (Table 3). Post-treatment and 1-month BDI-II scores were significantly lower than baseline $(p<.001)$, while 6 -month BDI-II scores were not $(p=$ 0.056)

Stroke survivors’ BDI-II scores were categorised into severity ratings (Table 3). At baseline, 59\% of stroke survivors had BDI-II scores within the moderate or severe categories, with 30\% in these categories at end of treatment. Stroke survivors' mean baseline scores on the BDI-II were categorised as moderate. Stroke survivors with more severe depression showed the greatest degree of change in scores from baseline to post-treatment. ${ }^{23}$ 
Mean HADSD scores changed significantly over time $(F(3,78.49)=3.96, p=.011)$.

HADSD scores at post-treatment $(p=.001)$ and 1-month $(p=.039)$, but not 6-months ( $p=.082)$, were significantly lower than at baseline.

\section{Anxiety}

A linear mixed model analysis testing time, group-attended and their interaction using fixed effects found significant effects on mean HADSA for time $(F(3,60.93)=3.34$, $p=.025)$ and group $(F(7,42.39)=2.30, p=.045)$ but not for their interaction. One-month HADSA post treatment scores were significantly lower than baseline $(p=.013)$, while post-treatment $(p=.068)$ and 6-month scores were not.

\section{Mixed Model Analysis for Carers}

Scores on BDI-II ( $p=.004)$ decreased significantly from baseline to 1-month ( $p=.014)$ and 6-month $(p=.001)$. There was no significant change over time for carers' HADSD scores. Mean HADSA scores decreased significantly over time $(p=.020)$ from baseline to 1-month $(p=.007)$ and 6-month $(p=.016)$.

Scores on the OCBS Time ( $\mathrm{p}=.008)$ decreased significantly from baseline to 1 month $(p=.020)$ and 6 months $(p=.002)$. OCBS Difficulty scores $(\mathrm{p}=.002)$ also similarly decreased at 1 month $(p=.003)$ and 6 months $(p=.001)$ (Table 4).

Carers' 6 month post-treatment scores were significantly lower than the end of treatment scores on the BDI-II ( $p=.013)$, OCBS Time $(p=.010)$ and OCBS Difficulty $(p=.021)$ subscales.

\section{Discussion}

We evaluated the implementation and acceptability of a group cognitive behavioural therapy (CBT) program (Brainstorm) for stroke survivors with depression, and their carers. Forty-eight stroke survivors (and their carers) were enrolled into 8 groups of the 
program; most attended $>80 \%$ of sessions offered. Anonymous feedback indicated that the group format was appealing; potentially due to being around others in a similar situation, development of mutual support, and increased socialisation. Depression scores at the end of Brainstorm were significantly lower than baseline. Demographic characteristics such as age, gender, number of strokes suffered, time since stroke and percentage of sessions attended were not associated with depression or anxiety scores over time in stroke survivors. This reduction in depression scores was sustained at 1month but not 6-months post treatment indicating that any benefits of the Brainstorm program ceased soon after group attendance stopped.

This study is one of very few evaluating the implementation and acceptability of group CBT for depression in stroke survivors. Gurr ${ }^{24}$ reported a decrease in depression and anxiety scores for 16 stroke survivors after up to three sessions of CBT and relaxation in an open group format within an acute stroke rehabilitation unit. We did not replicate their finding of a greater reduction in anxiety scores, possibly because the current group CBT intervention was targeted toward reduction of depression rather than anxiety.

The improvement in stoke survivors' depression was maintained at 1 month post treatment but not sustained. Drummond and Walker ${ }^{25}$ conducted a randomised controlled trial of a program designed to increase stroke survivors' leisure activities, and reported improvement in psychological wellbeing at 3 months which also did not persist at 6 months. The 6 month follow-up data in the current study came from a very small sample $(n=18)$. Further research is required to confirm whether the benefits of Brainstorm persist beyond one month.

Stroke survivors' mean baseline scores on the BDI-II were categorised as moderate, which is within the severity range considered to potentially benefit from group CBT interventions. $^{7}$ 
It was interesting to note that depression and anxiety scores for carers and perceived carer burden only decreased after the Brainstorm program was completed. This delayed reduction in scores may occur for several reasons. Stroke survivors' symptoms may have stabilised over time resulting in a decrease in the time and difficulty of tasks required of carers. Carers may have developed increased self-confidence in providing care over time. Alternatively, the Brainstorm program may have provided carers with CBT strategies to deal with their own mood, resulting in a flow-on effect of changing their perception of carer burden.

There are several limitations of the current study. This study had a small sample, and as it was an evaluation of existing service data, there was no control group. An inclusive approach to group admittance meant that some stroke survivors with minimal depressive symptoms were included, and group members had a broad range of levels of impairments. There was no evaluation of history of depression before stroke or formal diagnostic assessment of depression before entry to the Brainstorm program. Further, documentation of current use of antidepressant medication was not available, nor was there a measure of stroke severity. localisation or assessment of treatment integrity. Finally, as follow-up questionnaires were posted, the rate of return was low.

The low recruitment rates into the Brainstorm program may reflect referral barriers since Brainstorm was open to all inpatient and outpatient services. In fact, approximately 1000 strokes occur in the catchment area on an annual basis which suggests that larger numbers of stroke survivors would be eligible for Brainstorm. This may indicate a need for routine depression screening of people after stroke. There were also barriers explicitly expressed by stroke survivors and carers such as difficulty for stroke survivors in physically attending the group due to limited mobility, lack of transport or access to the facilities. In addition, some stroke survivors may prefer other 
types of treatment over a group therapy program. In depth interviews with participants at the final session may provide further information regarding group acceptability.

This study provides justification for the conduct of a randomised controlled trial to determine whether the benefits of the Brainstorm program occur above and beyond that of usual care control group, or ideally, an attention control group. Participants in a depression treatment trial would be systematically screened for depression and only those scoring above an agreed cut point on a standard screening instrument, or those with a DSM diagnosis, would be eligible for entry. This would also provide an opportunity to demonstrate the degree to which depressive symptom frequency and severity reduced pre-post intervention in comparison with controls. Our results also indicate that the inclusion of carers is recommended. In addition, given a Cochrane review ${ }^{26}$ has provided some evidence of effectiveness of talking therapies as a prevention strategy for depression after stroke, a second trial could examine the role of the Brainstorm program as a prevention strategy for post stroke depression. 


\section{References}

1. Hackett ML, Pickles K. Part 1: frequency of depression after stroke: an updated systematic review and meta-analysis of observational studies. Int J Stroke. 2014.

2. Hackett ML, Anderson CS. Predictors of Depression after Stroke: A Systematic Review of Observational Studies. Stroke. 2005;36:2296-301.

3. Ellis C, Zhao Y, Egede LE. Depression and increased risk of death in adults with stroke. J Psychosom Res. 2010;68:545-51.

4. Bakas T, Austin JK, Jessup SL, Williams LS, Oberst Mt. Time and difficulty of tasks provided by family caregivers of stroke survivors. J Neurosci Nurs. 2004;36(2):95-106.

5. Cameron JI, Cheung AM, Streiner DL, Coyte PC, Stewart DE. Stroke survivor depressive symptoms are associated with family caregiver depression during the first 2 years poststroke. Stroke. 2011;42:302-6.

6. Hackett ML, Anderson CS, House AO, Xia J. Interventions for treating depression after stroke. Cochrane Db of Syst Rev. 2008, issue 4.

7. Ellis PM, Hickie I, Smith DAR. Australian and New Zealand clinical practice guidelines for the treatment of depression. Aust NZ J Psychiat. 2004; 38:389-407.

8. Roth A, Fonagy P. What works for whom? A critical review of psychotherapy research. 2nd Ed. New York: The Guilford Press; 2005.

9. Laidlaw K. Post-stroke depression and CBT with older people. In: GallagherThompson D, Steffen AM, Thompson LW, editors. Handbook of Behavioural and Cognitive Therapies with Older Adults. New York: Springer Science + Business Media; 2008. p. 233-48.

10. Lincoln NB, Flannaghan T, Sutcliffe L, Rother L. Evaluation of cognitive behavioural treatment for depression after stroke: a pilot study. Clin Rehabil. $1997 ; 11: 114-22$ 
11. Rasquin SMC, van de Sande P, Praamstra AJ, van Heugten CM. Cognitivebehavioural intervention for depression after stroke: Five single case studies on effects and feasibility. Neuropsychol Rehabil. 2009;19(2):208-22.

12. Lincoln NB, Flannaghan T. Cognitive Behavioral psychotherapy for depression following stroke: A Randomised Controlled Trial. Stroke. 2003;34:111-5.

13. Thomas S, A, Walker M, Macniven JA, Haworth H, Lincoln NB.

Communication and Low Mood (CALM): a randomized controlled trial of behavioural therapy for stroke patients with aphasia. Clin Rehabil. 2012;27(5):398-408.

14. Vos T, Corry J, Haby MM, Carter R, Andrews G. Cost-effectiveness of cognitive-behavioural therapy and drug interventions for major depression. Aust NZ J Psychiat. 2005;39:683-92.

15. National Stroke Foundation. National Stroke Audit Acute Services Clinical Audit Report Melbourne, Australia: National Stroke Foundation; 2009 [cited 2013 August 17]. Available from: http://strokefoundation.com.au.

16. Hambridge JA, Turner A, Baker AL. Braveheart begins: pilot results of group cognitive behaviour therapy for depression and anxiety in cardiac patients. Aust N Z J Psychiat. 2009;43:1171-7.

17. Turner A, Hambridge JA, Baker AL, Bowman J, McElduff P. Randomised controlled trial of group cognitive behaviour therapy versus brief intervention for depression in cardiac patients. Aust NZ J Psychiat. 2013;47(3):235-43.

18. Edelman S, Lemon J, Kidman A. The perceived benefits of a group CBT intervention for patients with coronary heart disease. Journal of Cognitive Psychotherapy. 2003 2003;17(1):59-65(7).

19. Beck AT, Steer RA, Brown GK. BDI-II, Beck Depression Inventory: Manual. 2nd ed. San Antonio, Texas: Psychological Corporation; 1996. 
20. Zigmond AS, Snaith RP. The Hospital Anxiety and Depression Scale. Acta Psychiat Scand. 1983;67:361-70.

21. Meader N, Moe-Byrne, T, Llewellyn A, Mitchell AJ. Screening for poststroke major depression: a meta-analysis of diagnostic validity studies. J Neurol Neurosur Ps. 2014;85:198-206.

22. Aben I, Verhey F, Lousberg R, Lodder J, Honig A. Validity of the Beck Depression Inventory, Hospital Anxiety and Depression Scale, SCL-90, and Hamilton Depression Rating Scale as screening instruments for depression in stroke patients. Psychosomatics. 2002;43(5):386-93.

23. Bland JM, Altman DG. Measuring agreement in method comparison studies. Stat Methods Med Res. 1999;8:135-160.

24. Gurr B. A psychological well-being group for stroke patients. Clinical Psychology Forum. 2009;202(October):12-7.

25. Drummond A, Walker M. Generalisation of the effects of leisure rehabilitation for stroke patients. Brit J Occup Ther. 1996;59(7):330-4.

26. Hackett ML, Anderson CS, House AO, Halteh C. Interventions for preventing depression after stroke. Cochrane Db Syst Rev. 2008, issue 3. 


\begin{tabular}{|c|c|c|}
\hline Session Number & Session Title & Content \\
\hline 1 & $\begin{array}{l}\text { Introduction. So tell me what is this all } \\
\text { about? }\end{array}$ & $\begin{array}{ll}\text { - } & \text { Group introductions } \\
\text { - } & \text { Symptom screening and } \\
\text { feedback (BDI-II, HADS) } \\
\text { - } & \text { Introduction to mood } \\
\text { monitoring }\end{array}$ \\
\hline 2 & $\begin{array}{l}\text { Figuring out the problem: working out } \\
\text { what makes you feel bad. }\end{array}$ & $\begin{array}{l}\text { - } \text { The impact of stroke } \\
\text { - } \text { Stroke and mood } \\
\text { - } \quad \text { Psychoeducation } \\
\text { (depression/anxiety) } \\
\text { - Goal setting }\end{array}$ \\
\hline 3 & $\begin{array}{l}\text { If it aint broke, don't fix it: working out } \\
\text { what makes you feel good. }\end{array}$ & $\begin{array}{l}\text { - Link between activity and } \\
\text { mood } \\
\text { - Brainstorming - problem } \\
\text { - } \text { solving } \\
\text { - Activity planning }\end{array}$ \\
\hline 4 & $\begin{array}{l}\text { If it is broke... Part } 1 \text { Pros and cons for } \\
\text { change. }\end{array}$ & $\begin{array}{ll}\text { - } & \text { Problem solving } \\
\text { - Links between thoughts, } \\
\text { feelings and actions. } \\
\end{array}$ \\
\hline 5 & $\begin{array}{l}\text { If it is broke... Part 2: Overcoming barriers } \\
\text { to change }\end{array}$ & $\begin{array}{ll}\text { - } & \text { Barriers to change } \\
\text { - } & \text { Overcoming barriers } \\
\text { - } & \text { Thought challenging } \\
\end{array}$ \\
\hline 6 & $\begin{array}{l}\text { Helping change happen: Resources and } \\
\text { supports }\end{array}$ & $\begin{array}{l}\text { - Further problem solving } \\
\text { with a focus on increasing } \\
\text { motivation. } \\
\text { - } \quad \text { Managing conflict } \\
\text { - } \quad \text { Finding resources and } \\
\text { supports }\end{array}$ \\
\hline $7-9$ & $\begin{array}{l}\text { Dealing with the squeaky bits: Common } \\
\text { fears and problems } \\
\text { Discussion of topics of interest from group } \\
\text { participants }\end{array}$ & $\begin{array}{ll}\text { - } & \text { Sleeping problems } \\
\text { - } & \text { Dealing with emotional } \\
& \text { lability } \\
\text { - } & \text { Dealing with anxiety and } \\
\text { panic } \\
\text { - Information for carers } \\
\end{array}$ \\
\hline 10 & $\begin{array}{l}\text { BDI-II: Beck Depression Inventory } \\
\text { HADS: Hospital Anxiety and Depression } \\
\text { Scale. }\end{array}$ & 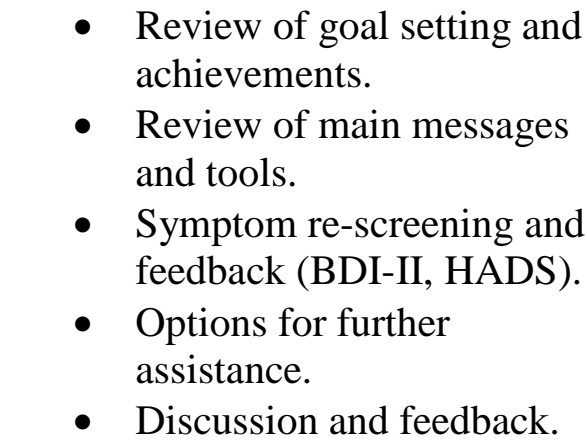 \\
\hline
\end{tabular}


Table 2.Baseline mean scores and standard error scores for stroke survivors for BDI-II and HADSA according to group they attended

\begin{tabular}{|c|c|c|c|c|c|c|c|c|}
\hline & Group1 & Group 2 & Group 3 & Group 4 & Group 5 & Group 6 & Group 7 & Group 8 \\
\hline No. stroke survivors/ group & 6 & 5 & 6 & 4 & 5 & 6 & 7 & 9 \\
\hline
\end{tabular}

\section{BDI-II}

Mean(SE)

22.24(3.91)

$30.41(4.77)^{*}$

23.33(4.71)

19.74(3.10) 11.09(3.60)*

13.47(3.33)

\section{HADSA}

Mean(SE)

$8.44(1.51)$

6.23(1.65)

$8.84(1.51)$

11.43(1.84)*

10.44(1.84)

9.35(1.53)

4.61(1.39)*

$6.20(1.28)$

*Significance level $p<.05$ 
Table 3.Estimated marginal means for stroke survivors for BDI-II, HADSD and HADSA at assessment time points

\begin{tabular}{lllll}
\hline & & \multicolumn{2}{c}{ Follow-Up } \\
Measure & Baseline & End of Treatment & 1 Month post & 6 Months post \\
& $(n=46)$ & $(n=37)$ & $\begin{array}{l}\text { treatment } \\
(n=22)\end{array}$ & $\begin{array}{l}\text { treatment } \\
(n=18)\end{array}$ \\
\end{tabular}

\section{BDI-II}

Mean (SE)

$23.66(1.54)$

$17.33(1.64)^{*}$

$16.14(2.09)^{*}$

$19.48(2.27)$

BDI-II Severity \%

Minimal(0-13)

Mild (14-19)

Moderate (20-28)

Severe (29-63)

HADSD

Mean (SE)

$8.54(0.63)$

$6.85(0.66)^{*}$

$7.23(0.75)^{*}$

$7.32(0.81)$

Time $F(3,78.49)=3.96(p=.011)^{*}$

HADSA

Mean (SE)

$9.28(0.62)$

$8.18(0.66)$
Time $F(3,61.64)=9.85(p<.001)^{*}$ Group $F(7,42.42)=2.26(p=.048)^{*}$
$11 \%$

$56 \%$

$6 \%$

$28 \%$

*Significance level $p<.05$ 
Table 4.Estimated marginal means for carers for OCBS Time and Difficulty subscales, BDI-II, HADSD and HADSA at assessment time points

\begin{tabular}{|c|c|c|c|c|c|}
\hline \multirow[b]{2}{*}{ Measure } & \multirow[b]{2}{*}{ Baseline } & \multirow[b]{2}{*}{ End of Treatment } & \multicolumn{2}{|c|}{ Follow-Up } & \multirow{2}{*}{$\begin{array}{c}\text { Significance } \\
p\end{array}$} \\
\hline & & & $\begin{array}{l}1 \text { Month post } \\
\text { treatment }\end{array}$ & $\begin{array}{l}6 \text { Months post } \\
\text { treatment }\end{array}$ & \\
\hline OCBS Time & $(n=29)$ & $(n=21)$ & $(n=12)$ & $(n=11)$ & \\
\hline Mean (SE) & $43.81(2.27)$ & $42.36(2.46)$ & $37.00(2.96)^{*}$ & $34.10(3.06)^{*}$ & $F(3,40.22)=4.52(p=.008) *$ \\
\hline \multicolumn{6}{|c|}{ OCBS Difficulty } \\
\hline Mean (SE) & $29.99(1.90)$ & $27.28(2.06)$ & $22.89(2.49)^{*}$ & $21.74(2.49)^{*}$ & $F(3,41.38)=5.93(p=.002)^{*}$ \\
\hline BDI-II & $(n=34)$ & $(n=24)$ & $(n=14)$ & $(n=11)$ & \\
\hline Mean (SE) & $11.62(1.31)$ & $9.83(1.51)$ & $6.93(1.87)^{*}$ & $4.55(1.99)^{*}$ & $F(3,48.01)=4.99(p=.004)^{*}$ \\
\hline \multicolumn{6}{|l|}{ HADSD } \\
\hline Mean (SE) & $4.65(0.59)$ & $4.20(0.66)$ & $3.42(0.78)$ & $3.20(0.85)$ & $F(3,51.18)=1.54(p=.214)$ \\
\hline \multicolumn{6}{|l|}{ HADSA } \\
\hline Mean (SE) & $7.12(0.61)$ & $6.41(0.69)$ & $4.78(0.84)^{*}$ & $4.84(0.93) *$ & $F(3,51.46)=3.57(p=.020)^{*}$ \\
\hline
\end{tabular}

*Significance level $p<.05$ 


\section{Figure Captions:}

Figure 1. Flow diagram of participant numbers at baseline, end of treatment assessment, 1-month and 6-months post treatment.

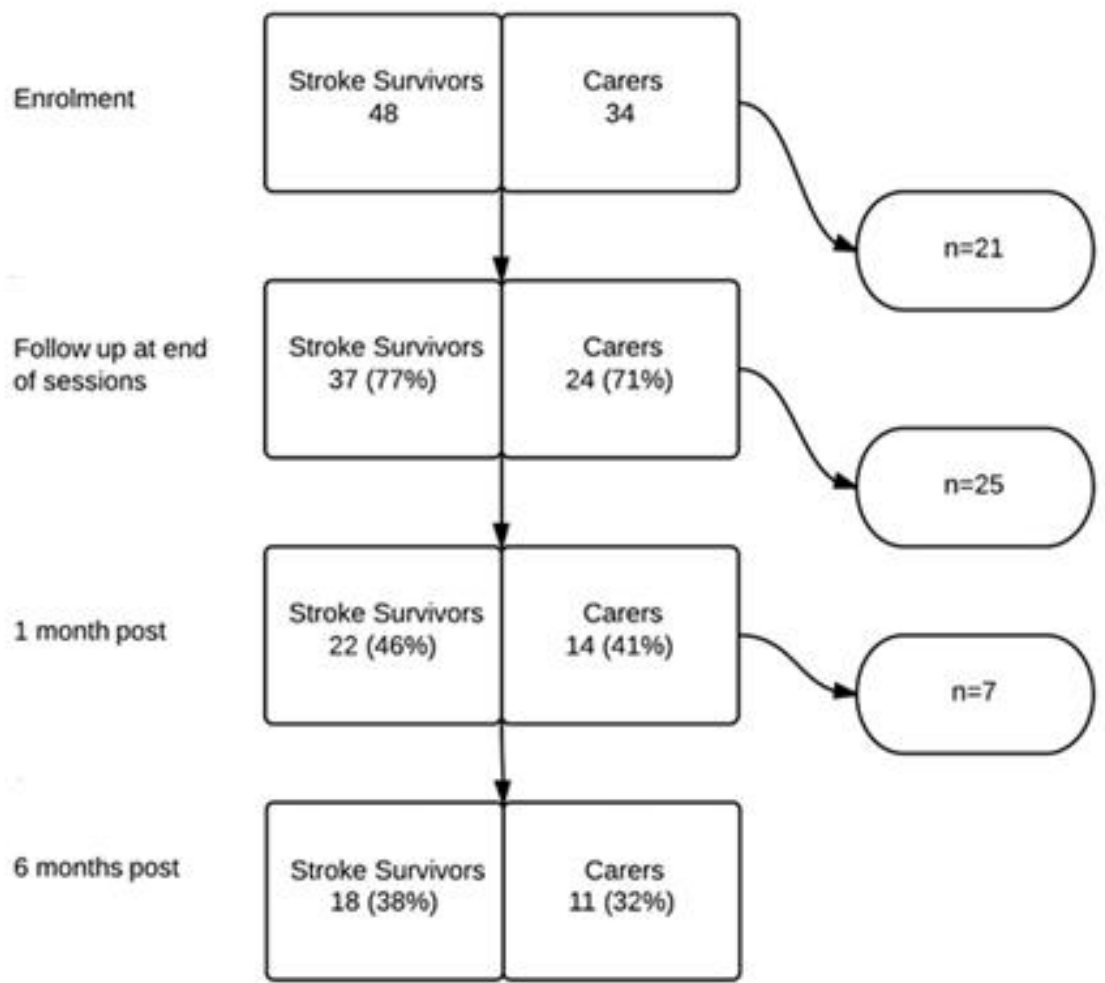

